\title{
FOOD INSTRUCTION BOOKLET DESIGN FOR THE NIGERIA FOOD CONSUMPTION AND NUTRITION SURVEY 2001-2003
}

Harris $E^{* 1}$, Dixon $B M^{2}$, Oguntona $\mathrm{TE}^{3}$, and C J ackson ${ }^{4}$

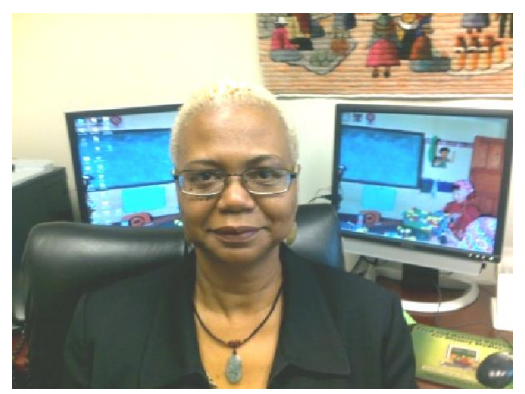

Ellen Harris

*Corresponding author email: ellen.harris@ars.usda.gov

${ }^{1}$ Beltsville Human Nutrition Research Center, Agricultural Research Service,

US Department of Agriculture, Bldg. 307C, Rm. 119, Beltsville, MD 20705, USA.

${ }^{2}$ International Institute of Tropical Agriculture, PMB 5320, Oyo Road, Ibadan, Oyo State, Nigeria.

${ }^{3}$ University of Agriculture-Abeokuta, Department of Nutrition, PMB 2240, Abeoukuta, Ogun State, Nigeria.

${ }^{4}$ US Agency for International Development, 1300 Pennsylvania Ave., NW, Washington, DC 20032 USA. 


\section{ABSTRACT}

In 2001-2003, the International Institute of Tropical Agriculture (IITA), in collaboration with the federal government of Nigeria, USAID and the US Department of Agriculture (USDA), conducted a nationwide food consumption survey. Since the last national survey occurred in 1963, a major objective was to establish national baseline data for women and children under 5 years old. To ensure the accuracy and quality of detailed food intake data, IITA adapted the USDA Food Instruction Booklet (FIB), a compilation of foods consumed in the country, divided into food groups and subgroups. A Nigerian food composition database formed the basis of the Nigerian FIB, whereby, food groups, probes, a food index, and measurement guides with conversion tables were compiled. The Nigerian FIB included 18 major food groups and 79 subgroups compared to 16 food groups and 100 subgroups in the USDA FIB. For both countries, these food groups highlight how food is categorized and consumed. A typical example was how each country grouped grains and cereals. The Nigerian FIB included four separate groups (cereals, cereal products, confectionaries, and pasta). In the USDA FIB, breads and sweet breads were put together as one group. Cereal, pasta and rice were together as a second group. Examples of these food groups and probes are presented. While both FIBs contained measurement guides (cups, spoons, thickness sticks, rulers), the Nigerian FIB also included indigenous guides. These guides allowed for food weight conversions using local utensils, weights of foods cooked at home and purchased away from home, weights of foods with different sizes, and weights of food items with different measuring tools. Another unique element in the Nigerian FIB was the inclusion of scientific names for foods, their English names, and local names in the three Nigerian languages (Hausa, Yoruba, Igbo). The FIB highlights cultural similarities and differences in food consumption and demonstrates how one country's survey instrument can be adapted to meet the needs of another.

K ey W ords: food instruction booklet, survey instrument 


\section{INTRODUCTION}

For a very long time nutritionists and dietitians in Nigeria had little to work with in terms of current information on the nutritional status of Nigerians. The last official national survey conducted in Nigeria was in 1963. For this reason nutritionists have had to depend on data from various area specific surveys, which did not have nutrition indicators as their major objectives [1-3].

In 2001-2003, the International Institute of Tropical Agriculture (IITA), in collaboration with the federal government of Nigeria, USAID and the US Department of Agriculture (USDA), conducted a nationwide food consumption survey. One objective of the survey was to establish a national baseline reference of food and nutrition status among women and children under 5 years old to facilitate future foodbased strategies and interventions [4]. The IITA adapted three USDA survey instruments to conduct the Nigeria survey: the survey operations plan, interviewer's manual, and the food instruction booklet (FIB) [5-7]. This paper demonstrates the adaptation of the USDA FIB to meet the needs of the Nigeria survey.

The accuracy and quality of a food survey depend on how much detail interviewers can obtain from their respondents. Just as the quality assurance procedures in controlled diet studies or the standardization of coding diet records minimize errors, efforts are needed to enhance the collection of food intake data [8-9]. An interviewer's ability to objectively prompt and probe the respondent to recall as much as possible is extremely important. To facilitate this aspect of the survey the FIB serves as a compilation of foods consumed in the country, divided into food groups and subgroups. For each food, key words are provided to probe or jog the respondent's memory about specific details.

\section{METHODS}

The nationwide survey covered 4 zones, 12 states (representing a third of the total states of the federation), 72 Local Government Areas (LGAs), 216 Enumeration Areas (EAs) and 30 households from each EA. The survey design considered relationships among (a) the agroecology and type of farming systems; (b) crops grown and food consumed; and (c) type of food consumed and micronutrient deficiencies. Thus, Nigeria was stratified according to major agroecological zones and predominant food crops within these zones. A total of 6,480 respondents were expected in the survey and the response rate was 81.2 percent $(\mathrm{N}=5,264)$. Specific details on survey design and operations may be found elsewhere [4].

\section{FIB Design}

A Nigerian food composition database provided the frame from which the food groups were derived for the Nigerian FIB [10]. Additionally, the Nigerian FIB contained several elements: 1) table of contents, 2) food groups, 3) probes, 4) a food index, and 5) measurement guides with conversion tables. Similar to the USDA FIB, the Nigerian FIB was organized on each page with three columns (Table 1). Column 
1 was the food/drink category. Column 2 contained a list of probes (key questions) for describing the food item such as the kind, type, form, brand of food; additions to the food; and whether the food was purchased or home made. Column 3 contained additional probes to enhance the respondent's memory and obtain information on how much food was consumed in terms of volume, size, number, or weight.

The Nigerian FIB had 18 major food groups and 79 subgroups compared to 16 food groups and 100 subgroups in the USDA FIB. In many ways these food groups typify how food is consumed and categorized in each country. For example, the USDA FIB grouped breads and sweet breads together as one group and cereal, pasta, and rice as a second group; whereas, the Nigerian FIB contained four separate groups (cereals, cereal products, confectionaries, and pasta). Fruits and vegetables are grouped together in the USDA FIB, but grouped as five separate groups (fruits, starchy fruits, legumes, roots and tubers, and vegetables) in the Nigerian FIB. The USDA FIB contained more processed food varieties (chips, puffs, twists, potato sticks; crackers; dip; popcorn; pretzels, breadsticks; nuts, seeds) compared to the Nigerian FIB snacks group (wheat-based, maize-based, other). Conversely, the USDA FIB included only one group for spreads, salad dressings, and oil. Whereas, the Nigerian FIB contained two separate groups; one for fats and oils and a second for oil seeds. A striking cultural difference occurred where the USDA FIB contained 6 separate groups for baby food, candy, desserts, pizza, sandwiches, and sauces, but there were no comparable food groups listed in the Nigerian FIB. Apendices A and B highlight these similarities and differences in the food groupings for both booklets.

The usual measurement guides (cups, spoons, thickness sticks, rulers) were used along with the probes to elicit the best estimate of how much food was consumed by the respondent. However, the Nigerian FIB also included a section on the use of indigenous measurement guides [10]. Table 2 lists examples of these guides, including conversions for weights of foods measured with local utensils, weights of foods cooked at home and purchased away from home, weights of foods with different sizes, and weights of food items with different measuring tools.

Another element of the Nigerian FIB was the general order of presentation for the foods in the booklets. In the USDA FIB the index included the food item name, the page number where the food could be found in the FIB, and the food group category. In the Nigerian FIB, the index included the scientific names for the food items, the English names, and local names in the three major Nigerian languages (Hausa, Yoruba, Igbo).

\section{DISCUSSION}

A concerted effort was made to assure the collection of quality food intake data for the Nigeria Food Consumption and Nutrition Survey. The FIB facilitated the training and standardization of the procedures used by the interviewers to solicit detailed information on the type, quality and quantity of foods eaten and fluids taken by the respondents. An unforeseen consequence of the FIB also was in the area of capacity 
building. Several Nigerian universities now use the instrument as a research and teaching tool to train future nutritionists.

While the USDA FIB was used as a model, the Nigerian FIB reflects African foods and eating patterns. In the Nigerian context, there are distinct groupings of foods. Fruits are consumed copiously when fresh and in season in Nigeria. Very little fruit is consumed as processed or packaged. Starchy fruits, legumes, and roots and tubers are viewed as separate groups because they constitute staples in various parts of the country. Oil seeds hold a prominent position in the diet and are grouped separately from fats and oils.

There are Nigerian foods that are essentially the same, but they have different names depending on the region of the country. Likewise, different foods may be called the same name. Additionally, there are regional variations in recipes and methods of preparation. The FIB helped to capture these diverse characteristics with its various probes and use of the 3 major languages in the country.

In recent years, new ingredients, flavor enhancers, and pre-packaged foods have been introduced. They are gradually changing traditional food recipes and preparation methods. Within the context of the survey, using the FIB to elicit more detailed information in turn meant revising and updating the existing Nigeria food composition database to analyze the 24-hour recall data.

\section{CONCLUSION}

The FIB highlights cultural similarities and differences in food consumption and demonstrates how one country's survey instrument can be adapted to meet the needs of another. Most studies on health and nutrition in Nigeria do not provide detailed information on foods eaten by the population. Nutritional status is presented either in terms of socio-cultural practices, height, weight, wasting, stunting, or clinical and biochemical attributes [11-16]. For food-based approaches to ameliorate malnutrition and support nutrition program policy, more information on actual foods consumed is needed. It is hoped that this description and discussion of the Nigerian FIB will be useful in the design and implementation of other African food consumption surveys and future studies.

\section{ACKNOW LEDGEMENTS}

This paper was written as a result of support for the Nigeria Food Consumption and Nutrition Survey by USAID under Grant Number 59-3148-0-013 and LAG-G-009300042-00 with contributions from UNICEF and Helen Keller International. 
Table 1: Example of FIB Page

\begin{tabular}{|c|c|c|}
\hline $\begin{array}{l}\text { Food/Drink } \\
\text { Category } \\
\left(\mathrm{C}_{1}\right)\end{array}$ & $\begin{array}{l}\text { Description of Food/Drink } \\
\left(\mathrm{C}_{2}\right)\end{array}$ & $\begin{array}{l}\text { How much of this } \\
\text { (Food) did you } \\
\text { actually (eat/drink)? } \\
\left(\mathrm{C}_{3}\right)\end{array}$ \\
\hline M aize & $\begin{array}{l}\text { VARIETY: What type of maize did you } \\
\text { take (white or yellow)? } \\
\text { FORM : In what form was it consumed? } \\
\text { (roasted, whole boiled, papped, or as meal } \\
\text { etc)? } \\
\text { PREPARATION: How was it prepared? } \\
\text { LIQUID: Was it made with milk, water? } \\
\text { Was the milk whole milk, low fat, or } \\
\text { skimmed? } \\
\text { SALT: Was salt used in the preparation? } \\
\text { FAT: Was any kind of fat or oil used in } \\
\text { the preparation? } \\
\text { OTHER INGREDIENTS: What other } \\
\text { ingredient was used in the preparation? } \\
\text { IN A M EAL: Was the maize consumed } \\
\text { as part of a meal? If "Yes," what are the } \\
\text { other components of the meal? } \\
\text { ADDITION: Did you add anything to it? } \\
\text { (water, sugar, honey, etc) Record each } \\
\text { addition on a separate line in the category } \\
\text { column... }\end{array}$ & $\begin{array}{l}\text { IF VOLUME: State } \\
\text { the amount (cup, bowl, } \\
\text { bottle) taken. } \\
\text { IF WEIGHT: State } \\
\text { the quantity (cup, tsp., } \\
\text { g., kg., etc.). Use } \\
\text { weight on label of } \\
\text { packet if available. } \\
\text { IF PLATE/BOWL: } \\
\text { How many? }\end{array}$ \\
\hline
\end{tabular}


Table 2:Indigenous M easurement Guides

\begin{tabular}{|c|c|c|}
\hline & Measuring Tool & Measure Conversion \\
\hline $\begin{array}{l}\text { Weights of foods } \\
\text { measured with local } \\
\text { utensils }\end{array}$ & $\begin{array}{l}\text { EMT (evaporated } \\
\text { milk tin) } \\
\text { - } \text { DTT (Derica tomato } \\
\text { tin) } \\
\text { - } \text { FSP (Family Support } \\
\text { Program bowl } \\
\text { - Re-packaged food by } \\
\text { price used to denote } \\
\text { quantity } \\
\text { - Schnapps bottle } \\
\text { - Ragolis water bottle }\end{array}$ & $\begin{array}{l}\text { - } 1 \text { kongo = } 10 \text { EMT } \\
\text { - } 1 \text { EMT }=\sim 2 \text { DTT } \\
\text { - } \mathrm{N} 5, \mathrm{~N} 10, \mathrm{~N} 50, \\
\mathrm{~N} 100, \text { etc. } \\
\text { - } 1 / 4 \text { or full }(.75 \text { liter }) \\
\text { - } 1.5 \text { or } .75 \text { liter }\end{array}$ \\
\hline $\begin{array}{l}\text { Weights of foods cooked } \\
\text { at home and purchased } \\
\text { from canteen/restaurants }\end{array}$ & $\begin{array}{l}\text { - Re-packaged food by } \\
\text { price used to denote } \\
\text { quantity } \\
\text { - Foam models } \\
\text { representing } 3 \text { model } \\
\text { sizes also used }\end{array}$ & $\begin{array}{l}\text { - } \quad \text { 5, N10, N50, } \\
\text { N100, etc.) }\end{array}$ \\
\hline $\begin{array}{l}\text { Weights of foods with } \\
\text { different sizes }\end{array}$ & $\begin{array}{ll}\text { - } & \text { Small } \\
\text { - } & \text { Medium } \\
\text { - } & \text { Large } \\
\text { - } & \text { Extra large }\end{array}$ & $\begin{array}{l}\text { - Based on weight } \\
\text { food type }\end{array}$ \\
\hline
\end{tabular}


Appendix A: Comparison of Food Groups in USDA FIB and Nigerian FIB: All Groups

\begin{tabular}{|l|l|}
\hline USDA FIB & Nigerian FIB \\
\hline 1. Baby foods, formulas, juices & 1. Beverages \\
2. Beverages, milk, cream & 2. Cereals \\
3. Breads, sweet breads & 3. Cereal products \\
4. Candy, syrups, sweeteners & 4. Confectionaries \\
5. Cereals, pasta, rice & 5. Pasta \\
6. Cheese, eggs, yogurt & 6. Milk and dairy products \\
7. Desserts, ice cream, frozen yogurt & 7. Fats and oils \\
8. Fruits, vegetables & 8. Fruits \\
9. Meat, poultry, fish, shellfish & 9. Starchy fruits \\
10. Pizza, tacos, frozen meals & 10. Legumes \\
11. Mixed dishes, macaroni and & 11. Meat and meat products \\
cheese, spaghetti with sauce & 12. Oil seeds \\
12. Sandwiches & 13. Poultry and eggs \\
13. Salads, soups & 14. Roots and tubers \\
14. Sauces, gravies & 15. Sea foods \\
15. Snacks & 16. Vegetables \\
16. Spreads, salad dressings, oil & 17. Snacks \\
& 18. Dishes \\
\hline
\end{tabular}


Appendix B 1: Comparison of Food Groups in USDA FIB and Nigerian FIB: Beverages, Dairy, Breads \& Cereals

\begin{tabular}{|c|c|}
\hline USDA FIB & Nigerian FIB \\
\hline 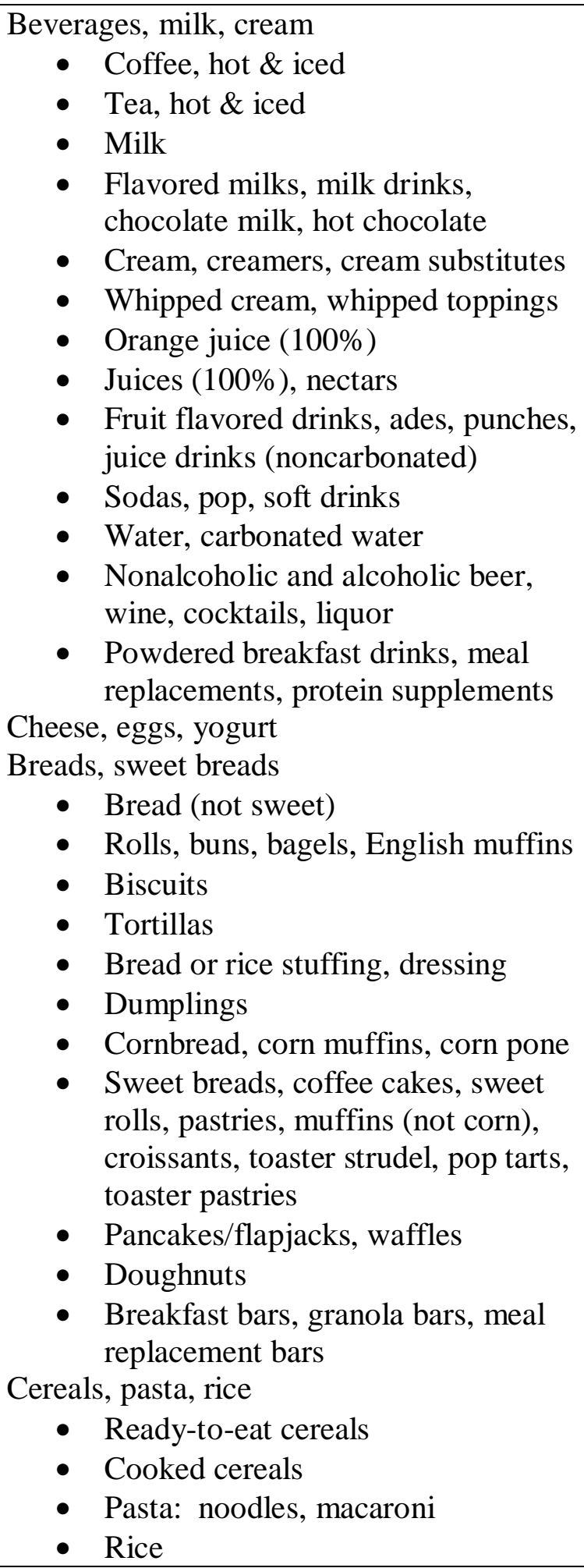 & 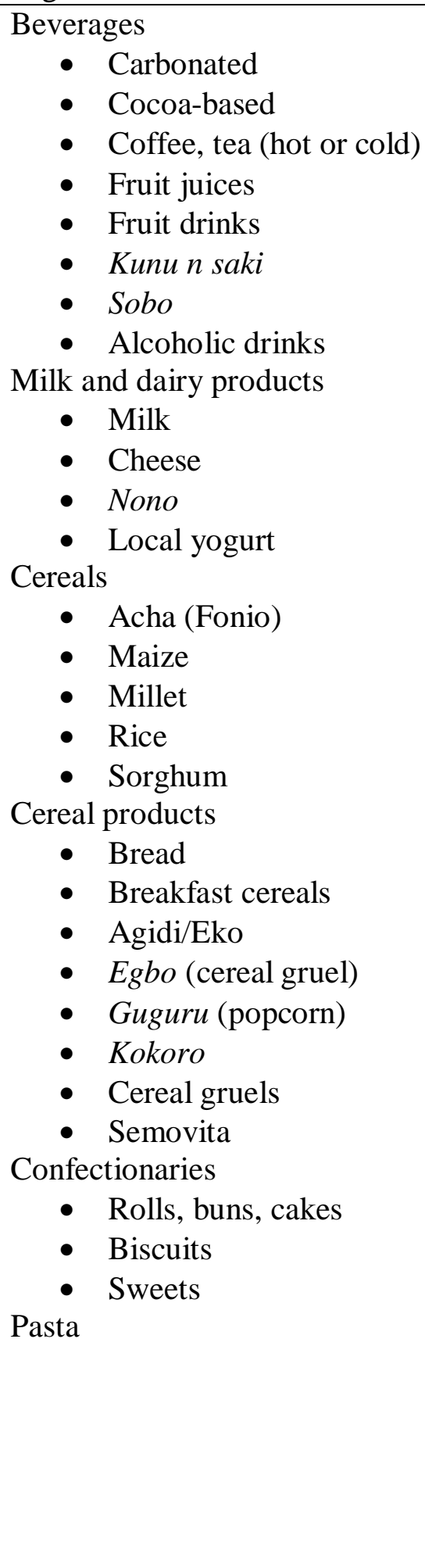 \\
\hline
\end{tabular}


Appendix B2: Comparison of Food Groups in USDA FIB and Nigerian FIB: Fruit, V egetables, M eat, Poultry, \& Seafood

\begin{tabular}{|c|c|}
\hline USDA FIB & Nigerian FIB \\
\hline $\begin{array}{l}\text { Fruits, vegetables } \\
\text { - Fruits, berries } \\
\text { - White potatoes } \\
\text { - French fries, tater tots } \\
\text { - Sweet potatoes } \\
\text { - Vegetables, dry beans } \\
\text { - Pickles } \\
\text { - Olives } \\
\text { Meat, poultry, fish, shellfish } \\
\text { - Beef, lamb, veal, game meats } \\
\text { - Ham or pork } \\
\text { - Deli meats, packaged lunch meats, } \\
\text { - Liver, organ meats } \\
\text { - Bacon } \\
\text { - Sausage } \\
\text { - Jerky, dried meat } \\
\text { - Poultry } \\
\text { - Fish, shellfish }\end{array}$ & 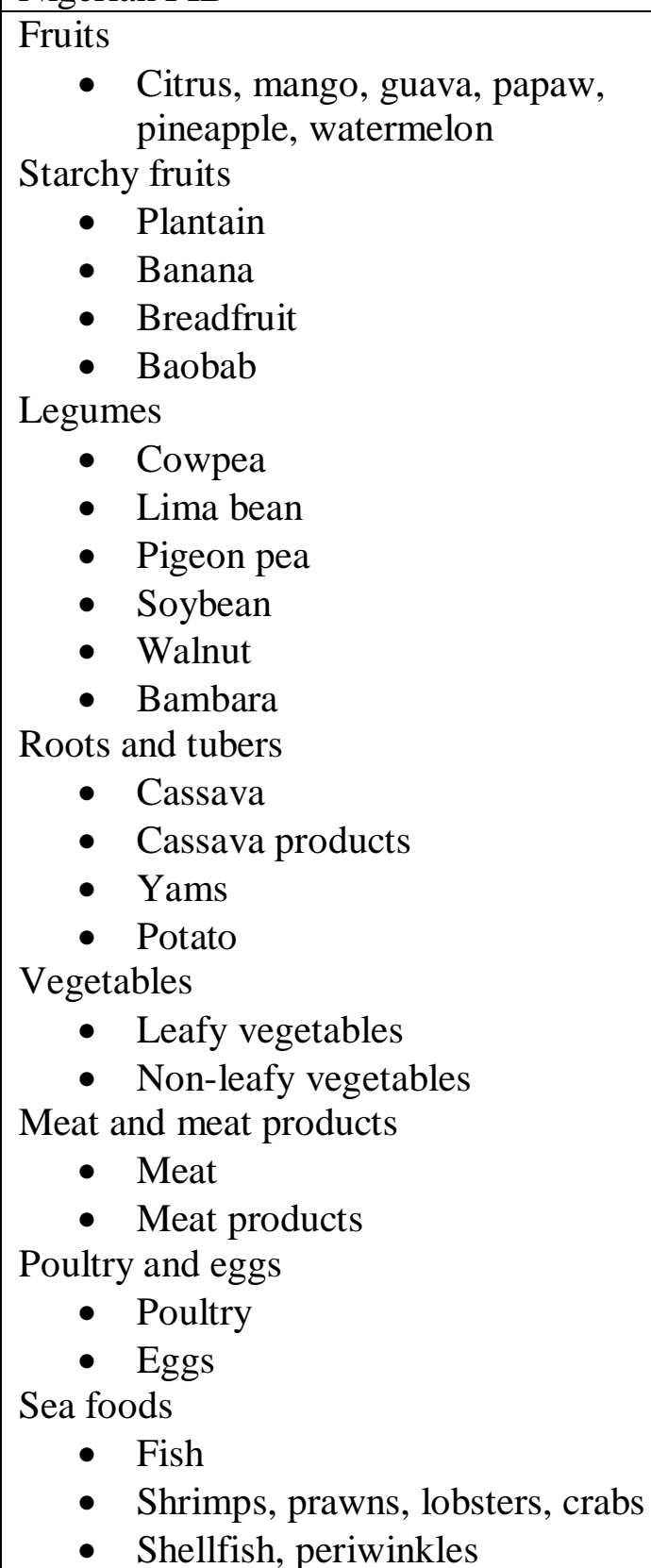 \\
\hline
\end{tabular}


Appendix B 3: Comparison of Food Groups in USDA FIB and Nigerian FIB: $M$ ixed Dishes, Snacks, Oils, Other Foods

\begin{tabular}{|c|c|}
\hline USDA FIB & Nigerian FIB \\
\hline 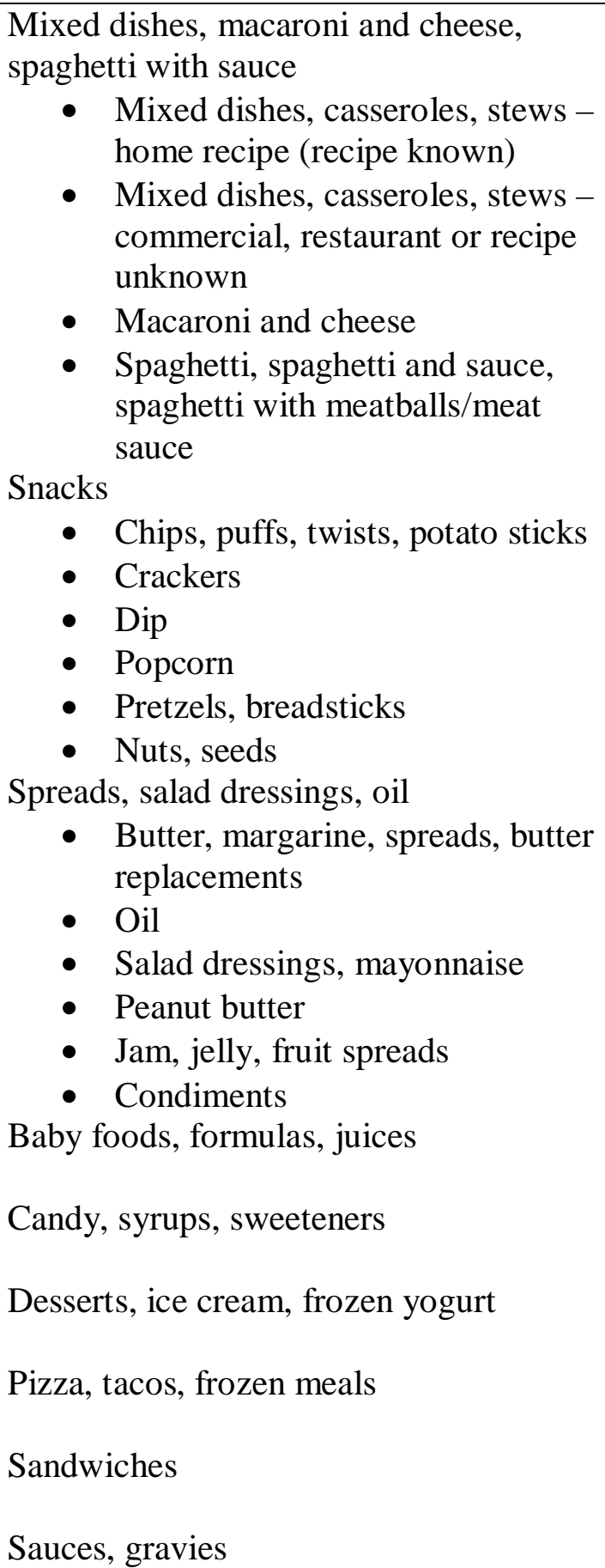 & 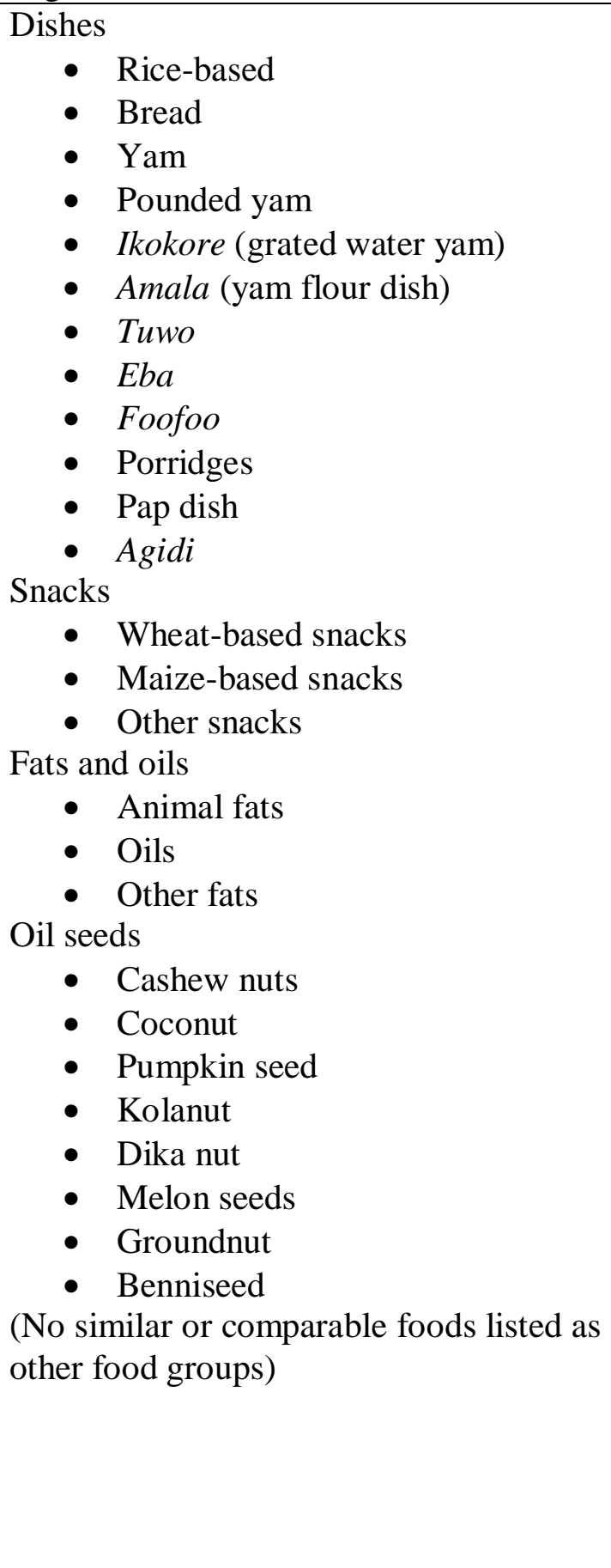 \\
\hline
\end{tabular}




\section{REFERENCES}

1. Federal Office of Statistics. Nigeria Demographical and Health Survey, Nigeria, Lagos, Nigeria, 1990.

2. Federal Government of Nigeria/UNICEF. Report of the Multiple Indicators Cluster Survey (MICS). UNICEF Country Office, Nigeria, 1995.

3. Federal Office of Statistics. Nigeria Demographical and Health Survey, Nigeria, Lagos, Nigeria, 1999.

4. Maziya-Dixon B, Akinyele IO, Oguntona EB, Nokoe S, Sanusi RA and E Harris Nigeria Food Consumption and Nutrition Survey 2001-2003 Summary. Ibadan, Nigeria, International Institute of Tropical Agriculture, 2004.

5. United States Department of Agriculture. What We Eat in America: 19941996, Survey O perations Plan, Rockville, MD, Westat, Inc. 1996.

6. United States Department of Agriculture. What We Eat in America: 19941996. Interviewer's M anual. Rockville, MD: Westat, Inc. 1996.

7. United States Department of Agriculture. What We Eat in America: 19941996. F ood Instruction B ooklet. Rockville, MD: Westat, Inc. 1996.

8. Conway R, Robertson C, Dennis B, Stamler J, Elliott P and INTERM AP Research Group Standardised coding of diet records: experiences from INTERMAP UK. Br. J. Nutr. 2004; 91:765-71.

9. M ost M M , Craddick S, Crawford S, Redican S, Rhodes D, Rukenbrod F, Laws R, and Dash-Sodium Collaborative Research Group Dietary quality assurance processes of the DASH-Sodium controlled diet study. J. Am. Diet. Assoc. 2003; 103:1339-46.

10. Oguntona EB and IO Akinyele Nutrient Composition of Commonly Eaten Foods in Nigeria - Raw, Processed and Prepared, Ibadan, Nigeria, Food Basket International Publication Series, 1995.

11. A bidoye RO and PA Akande Nutritional status of public primary school children: a comparison between an upland and riverine area of Ojo LGA, Lagos State, Nigeria. Nutr. H ealth 2000; 14:225-240.

12. A bidoye RO and AP Pearce Nutritional status of nursery school children: a comparison between Lagos State (Southern Nigeria) and Jos, Plateau State (Northern Nigeria). Nutr. H ealth 2000; 14:241-256.

13. Ajayi 10 and 00 A kinyinka Evaluation of the nutritional status of first year school children in Ibadan, Southwest Nigeria. Afr. J. M ed. Sci. 1999; 28:59-63. 
14. A nsa VO, O digwe $\mathrm{CO}$ and MU Anah Profile of body mass index and obesity in Nigerian children and adolescents. Niger J. Med. 2001; 10:78-80.

15. Ene-Obong HN, Enugu GI and AC U waegbute Determinants of health and nutritional status of rural Nigerian women J. Health Popul. N utr. 2001; 19:320330.

16. Esimai OA, Ojofeitimi EO and OM Oyebowale Sociocultural practices influencing under 5 nutritional status in an urban community in Osun State, Nigeria. Nutr. Health 2001; 15:41-46. 